
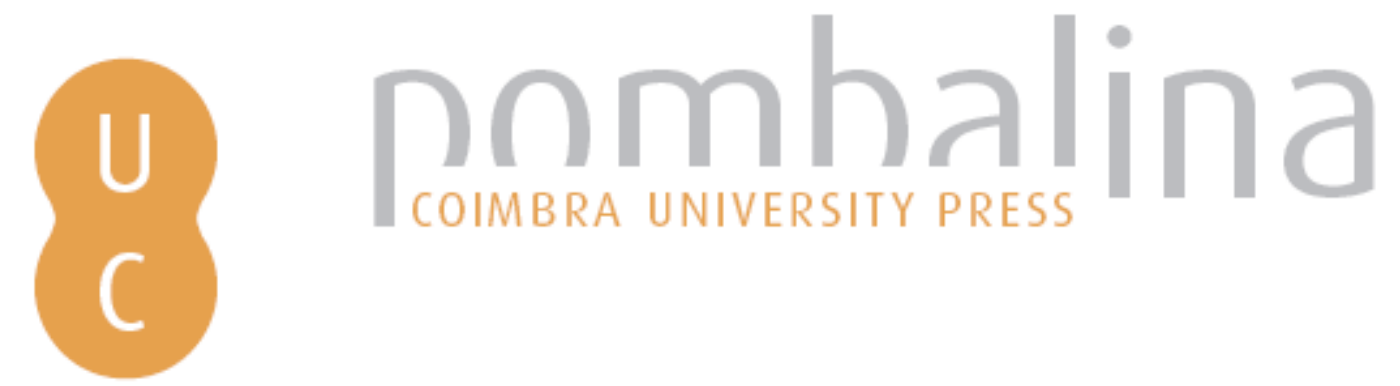

\title{
Letramentos digitais, linguagens, comunicação online e implicações em processos de formação na universidade
}

\author{
Autor(es): $\quad$ Fernandes, Terezinha \\ Publicado por: Imprensa da Universidade de Coimbra \\ URL \\ persistente: URI:http://hdl.handle.net/10316.2/47382 \\ DOI: $\quad$ DOl:https://doi.org/10.14195/978-989-26-1716-9_6 \\ Accessed : $\quad$ 26-Apr-2023 14:42:18
}

A navegação consulta e descarregamento dos títulos inseridos nas Bibliotecas Digitais UC Digitalis, UC Pombalina e UC Impactum, pressupõem a aceitação plena e sem reservas dos Termos e Condições de Uso destas Bibliotecas Digitais, disponíveis em https://digitalis.uc.pt/pt-pt/termos.

Conforme exposto nos referidos Termos e Condições de Uso, o descarregamento de títulos de acesso restrito requer uma licença válida de autorização devendo o utilizador aceder ao(s) documento(s) a partir de um endereço de IP da instituição detentora da supramencionada licença.

Ao utilizador é apenas permitido o descarregamento para uso pessoal, pelo que o emprego do(s) título(s) descarregado(s) para outro fim, designadamente comercial, carece de autorização do respetivo autor ou editor da obra.

Na medida em que todas as obras da UC Digitalis se encontram protegidas pelo Código do Direito de Autor e Direitos Conexos e demais legislação aplicável, toda a cópia, parcial ou total, deste documento, nos casos em que é legalmente admitida, deverá conter ou fazer-se acompanhar por este aviso.

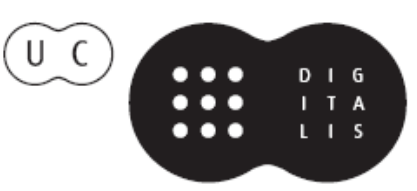



TEREZINHA FERNANDES

Universidade Federal de Mato Grosso (UFMT)

terezinha.ufmt@gmail.com

\section{LETRAMENTOS DIGITAIS, LINGUAGENS, COMUNICAÇÃO ONLINE E IMPLICAÇÕ ES EM PROCESSOS DE FORMAÇÃO}

NA UNIVERSIDADE

\section{Considerações Iniciais}

Na cibercultura os processos de comunicação online requerem dos sujeitos conhecimentos específicos para operar com diferentes meios, dispositivos e interfaces, modos de interação, gêneros digitais e linguagens. Nos diferentes contextos culturais em que os letramentos digitais (LD) se desenvolvem, estes podem ser concebidos como uma prática social que comporta eventos por meio dos quais emergem outros letramentos.

No âmbito de práticas de letramento digitais (PLD) e eventos de letramento digital (ELD) as competências de comunicação e linguagens a desenvolver em estudantes online, são questões fundamentais. A partir disso é possível compreender como, onde e em que condições as apropriações e produções podem ocorrer em tais processos, e ainda, os seus desdobramentos em processos de formação.

As mudanças nas maneiras dos sujeitos atuarem na cibercultura e os efeitos de sentidos por eles atribuídos são mobilizadores de LD. É possível desenvolver habilidades de planejamento e criação de produtos culturais de comunicação hipertextual, hipermodal e hipermidiático, com linguagens visuais, sonoras e verbais e o seu compartilhamento por diversos modos.

Em seus cotidianos os sujeitos vivenciam múltiplas práticas sociais, o que faz com que cheguem aos cursos universitários com uma gama cada vez maior 
de conhecimentos que refletem nos modos de aprender, se comunicar, se relacionar e interatuar no mundo digital.

O texto apresentado é o recorte de uma pesquisa de doutorado desenvolvida no Brasil, com doutoramento sanduíche em Portugal realizada por Souza (2016). O estudo citado discutiu os letramentos digitais (LD) de estudantes online na universidade portuguesa e, neste recorte, o objetivo é discutir aspectos teóricos dos LD especificamente na dimensão da comunicação online e das linguagens do meio digital, evidenciar as habilidades e competências que podem favorecer a mobilização de outros letramentos e problematizar implicações e desdobramentos em processos de formação.

Com tal intenção o texto estrutura-se em quatro partes. A primeira discute as linguagens híbridas nos processos de comunicação na cibercultura; a segunda aborda a comunicação online fazendo o uso das diversas linguagens do meio digital; a terceira focaliza os LD do ponto de vista de suas habilidades e competências de uso das linguagens na comunicação online; e nas considerações finais faz-se uma retomada ao tema destacando implicações e desdobramentos destes processos na universidadade.

\section{Linguagens híbridas}

A vitalidade da digitalização permitiu a distribuição da informação em rede indo "desembocar na explosão da internet" (Santaella, 2005, p. 24), como resultado da conjunção de duas ideias simples: 1) a informação distribuída em rede; e 2) o hipertexto - texto digitalizado, fluido, reconfigurável à vontade, que se organiza de modo não linear, em arquiteturas reticulares. Essas duas aplicações já eram úteis isoladamente, mas sua associação criou uma rede viva e dotada de propriedades emergentes de linguagens na comunicação.

No contexto contemporâneo, conforme Santaella (2005) a relação da cibercultura como espaço de comunicação e os seus múltiplos pontos ou nós, fazem com que as linguagens se abram em janelas e superlinks, em um movimento que não cessa de se atualizar em forma de palavras, sons, imagens e outros signos. 
Estas linguagens, para a autora citada, são mobilizadas na comunicação/ interação entre interlocutores em seus processos dialógicos de produção e construção de sentidos pelas vozes sociais e os diversos discursos polifônicos que circulam em um fluxo livre de informações. Tais linguagens materializam-se pelo evento comunicacional conhecido como hipertexto, como uma teia, com múltiplas conexões para organizar e produzir conhecimentos por entre diversos suportes, interfaces e gêneros digitais.

A linguagem como um processo de interação social leva em conta as situações interacionais, focalizando o contexto sócio histórico e seus condicionantes políticos, ideológicos, culturais etc (Vigotsky, 1987). Em situações imediatas de comunicação, em uma abordagem dialógica e polifônica, os gêneros do discurso são fundados na heterogeneidade (Bakhtin, 2011), constituindo-se a base para a compreensão dos letramentos digitais (LD) e suas práticas, em que as mídias digitais são mediadoras entre os sujeitos e estes processos.

As linguagens como uma rede, conforme Santaella (2005), em constante movimento pela multilinearidade, heterogeneidade, interatividade, intertextualidade, interdisciplinaridade, dialogismo e polifonia, contribuem para que a mensagem seja construída na interação entre os sujeitos no/do processo comunicacional, como autores e co-autores em um processo dialógico (Bakhtin, 2011). Nesses processos, a interação entre os interlocutores é um princípio fundamental para que a linguagem possibilite a comunicação, o sentido e a significação para a compreensão do diálogo que é ininterrupto.

De acordo com Deleuze (2010, p. 15), é necessário conceber a linguagem "como um integrando (de signos), compreendendo suas próprias variações constitutivas de uma história universal e fazendo com que cada fragmento fale por sua própria voz”. São processos em que os signos lingüísticos, significado/ conceito e significante/imagem sonora, são percebidos como unidades portadoras de sentido na comunicação.

Para Barthes (2004), na cultura as linguagens se diferenciam e se dividem. Recebemos várias linguagens culturais pelos diversos meios o dia todo. As participações, interações, produções, autorias e recriações nos espaços virtuais contemporâneos comportam múltiplos jogos de linguagens que ecoam simultânea e sincronamente, longínquas e próximas, anô- 
nimas e personalizadas, inapreensíveis e compreensíveis e multiplicam-se em um movimento contínuo.

Os processos virtuais e convergentes das linguagens em nossos cotidianos operam forças que se atualizam e sintetizam-se em mudanças nos sistemas de representação, como a escrita, pintura, desenho, fotografia, arte, sistemas comunicação, dentre outros e se intercambiam em novos espaços e artefatos de comunicação, pois, consoante com Bakhtin (2011, p. 259) "os diversos campos da atividade humana estão ligados ao uso da linguagem".

Nas práticas discursivas e eventos de linguagem realizados no ciberespaço, de modo análogo ao discurso heterogêneo e polifônico (Bakhtin, 2011), as linguagens são praticadas por sujeitos sociais, históricos e ideológicos, por isso, refletem vozes sociais. Nessa acepção o ciberespaço é um espaço-lugar de encontro destas diferentes vozes que mantêm relações de controle, negociação, compreensão, concordância, discordância e discussão em práticas cotidianas de uso, apropriação, produções coletivas e colaborativas, resultantes de trocas e interações construídas socialmente.

As misturas das linguagens em Santaella (2005, p. 21), tais como a dança (entre o visual e o sonoro), a linguagem verbal oral (mistura do verbal, sonoro e mesmo visual, na gestualidade de que se faz acompanhar) etc, "se constituem numa chave para a compreensão das linguagens híbridas" ".

Toda a complexidade de linguagens, para Santaella (2005), se multiplica e se desdobra em outras por um processo de virtualização, na e pela interação entre interlocutores produtores de discursos. Nesse processo as atribuições de sentidos são mediados pelos contextos social, ideológico, cultural, tecnológico etc.

Assim, as linguagens digitais que permeiam os processos de comunicação pela informação distribuída por servidores interconectados pela internet articulam o hipertexto e a hipermídia, e operam pela estrutura complexa e não

1 As linguagens híbridas (literatura, música, teatro, desenho, pintura, gravura, escultura, arquitetura etc), e a variedade de suportes, meios, canais (foto, cinema, televisão, vídeo, jornal, rádio, computador etc), pelos quais estas se materializam e são veiculadas, se originam de apenas três matrizes de linguagem e pensamento: a verbal, a sonora e a visual, em processos de combinação e mistura, originando todas as demais formas de linguagens e processos sígnicos produzidos historicamente pelos seres humanos (Santaella, 2005). 
linear da informação, misturando textos escritos, grafismos, símbolos, notações, diagramas, figuras e todas as espécies de elementos audiovisuais (voz, música, sons, imagens fixas e animadas), em que,

os programas multimídia (softwares) literalmente programam as misturas de linguagem a partir de fontes primordiais; os signos audíveis ou sonoros (sons, músicas, ruídos), os signos imagéticos (todas as imagens de imagens fixas a animadas) e os signos verbais (orais e escritos) (Santaella, 2005, p. 25).

As linguagens híbridas em suas formas e movimentos, em redes, estão conforme Santaella (2005), organizadas em arquiteturas hiper, visto que cada informação estocada é sempre recuperada por cada usuário por caminhos alineares e percursos próprios em um vasto labirinto de possibilidades.

$\mathrm{Na}$ inter-relação entre as diversas linguagens e seus desdobramentos nos espaços incorpóreos da virtualidade o leitor/usuário/navegador da hipermídia, como aponta Santaella (2004; 2005), coloca em ação diversos mecanismos e habilidades para a leitura, escrita e produção-autoria, como as perceptivas; sensório motoras; e cognitivas. Estas novas formas de percepção e cognição, emergem pelos suportes digitais, estruturas híbridas e alineares da hipermídia, possibilitando determinadas disposições que habilitam os sujeitos à recepção e resposta aos signos das mídias digitais para navegar por fluxos informacionais híbridos, voláteis e líquidos - sonoros, visuais e verbais.

Conforme aponta Santaella $(2004 ; 2005)$ o fato de uma pessoa não possuir o domínio da leitura e da escrita convencional, mas, navegar na internet por meio da iconicidade do dispositivo ou interface, reforça a ideia de que os LD precedem a alfabetização convencional. As habilidades (topográficas) de acionar comandos, são habilidades que não dependem, inicialmente, do domínio da leitura e da escrita concencional pelo sujeito para atuar em situações sociais.

No cenário cibercultural atravessado pelas linguagens híbridas, a interatividade, a emissão e a recepção e as transformações socioculturais geram outras formas de acesso à informação, construção de conhecimento e heterogeneidade na comunicação. Em espaços sociais e combinação de artefatos culturais 
de comunicação as linguagens "são tão multiformes quanto os campos da atividade humana" (BAKHTIN, 2011, p. 259).

Diante de tais apontamentos percebe-se que a hibridez das linguagens, possibilitada pela informação distribuída em rede, na lógica do hipertexto e da hipermídia, favorecem uma infinidade de associações e a produção de outras linguagens para o uso no meio digital, e estas potencializam habilidades e competências para a comunicação online, conforme discute-se no próximo item.

\section{A comunicação online}

A cibercultura como espaço de comunicação e a linguagem como processo de interação social, abarcam a multimodalidade dos gêneros do discurso presente na hipermídia e no hipertexto que, conforme Santaella (2005), é um aspecto importante a ser considerado nos letramentos na cibercultura, tendo em vista:

QUADRO 1: Multimodalidade dos gêneros do discurso em ambiente hipermídia

\begin{tabular}{|l|l|}
\hline \multicolumn{2}{|c|}{ Aspectos relacionados } \\
\hline 1) forma & $\begin{array}{l}\text { em diferentes tipos de discursos (dissertativos, argumentativos, } \\
\text { informativos, comparativos, interpretativos etc); }\end{array}$ \\
\hline 2) organização & em arquiteturas flutuantes de nós e nexos reconfiguráveis; \\
\hline 3) complementaridade & $\begin{array}{l}\text { atrações, repulsas e fusões entre o verbal, o sonoro e o visual, } \\
\text { em uma mistura de infinitas linguagens. }\end{array}$ \\
\hline
\end{tabular}

Fonte: Elaborado pela autora com base em Santaella (2005).

Nestas linguagens usadas na comunicação online assíncrona e mais acentuadamente nos diálogos síncronos (chat, hangout etc) para suprir a ausência da linguagem corporal, tom de voz, expressão facial, olhar, e emoção face a face, recorre-se também a diversos símbolos para expressar as marcas na fala. Marcuschi (2006) destaca que tais marcas podem ser verbais, não lexicais, não-verbais e supra-segmentais: 
QUADRO 2: Marcas da linguagem verbal oral

\begin{tabular}{|l|l|}
\hline Marcas da fala & Características \\
\hline Verbais & estereotipação por conectores, preposições, advérbios - "só acho"; \\
\hline Não-verbais & gestos - \o/; olhares - ;), risos :D; \\
\hline Supra-segmentais & $\begin{array}{l}\text { características prosódicas - pausas, tons, ritmos, elipses, hesitações } \\
\text { e ênfases. }\end{array}$ \\
\hline
\end{tabular}

Fonte: Elaborado pela autora com base em Marcuschi (2006).

O uso destas marcas da linguagem, na comunicação online, é uma habilidade necessária, visto que a adequação do discurso ao contexto e situação de uso em meio online é importante. Em um contexto de comunicação síncrona usar onomatopéia (emoticons) e oralizações (abreviações, gírias ou ênfases para marcar tom de voz, estado de humor, hesitação, pausa) e outras marcas próprias desse tipo de comunicação ajuda a tornar o diálogo mais fluido e ágil. Todavia, em um artigo ou texto acadêmico o uso de tais marcas demonstra inadequação da linguagem, conforme as normas que esta produção textual exige.

No processo de convergência de mídias digitais presente no ciberespaço, abre-se um leque para a diversidade de linguagens que se desdobram em outras formas, signos, gêneros textuais, hipertextos etc., (Santaella, 2005), e nesta ampla rede de sentidos heterogêneos, polifônicos e multiformes (Bakthin, 2011), novas apropriações, produções e compartilhamentos são potencializados pelas ações dos sujeitos sociais.

Tais aspectos, observados por Souza (2016) nas interações entre estudantes em ambientes virtuais de amprendizagem, apontam para a dimensão linguística dos LD que se configura em conhecimentos e habilidades fundamentais no âmbito de cursos online, materializadas em situações de comunicação síncrona em que a linguagem híbrida (visual, sonora e verbal) com marcas da oralidade, da gestualidade e da escrita, entremeadas aos aspectos socioculturais, ideológicos e políticos da linguagem que emergem em tais práticas sociais.

Desse modo, as linguagens híbridas fundantes nos processos de comunicação online e suas variações constitutivas de significados e sentidos favorecem 
as apropriações e produções de conhecimentos que, por sua vez, contribuem para a mobilização de habilidades e competências dos LD como se discute no tópico seguinte.

\section{Os letramentos digitais}

O domínio para o uso das diversas linguagens do meio digital requer a compreensão deste sistema como um emaranhado de mídias, que se influenciam reciprocamente, com uma gama imensa de formatos, suportes e gêneros que por eles são veiculados (o impresso, a TV, o rádio, o telefone, o cinema, o computador, a internet, os dispositivos móveis etc,) e se misturam em práticas sociais cada vez mais migratórias em função das mudanças e avanços que têm ocorrido nas sociedades contemporâneas.

Estas práticas sociais de uso das linguagens que circulam no ciberespaço (Lévy, 1999), possibilitam atuar, interagir e se comunicar online em tempos e espaços diferentes de até pouco tempo. Segundo Lévy (1993) a linguagem como poderoso instrumento que a humanidade possui para registrar sua memória e propagar suas representações, tem tanto a oralidade primária, quanto a escrita e a informática, como formas de pensar e de se comunicar nas sociedades atuais.

No movimento dos processos de comunicação no contexto digital, há diferentes formas de linguagens que se integram como as verbais, icônicas, sonoras, visuais, dentre outras, as quais proporcionam outros modos de se comunicar, pensar, criar, coaprender e ensinar nas práticas e contextos sociais de diversos grupos e se traduzem por um processo chamado de cultura da convergência (Jenkins, 2009), entre dispositivos, meios e mensagens.

No interior dessa reorganização conforme Chartier (1998) há mudanças nos modos de participação dos sujeitos em sociedade, no intercâmbio de ideias, nas práticas com os diferentes suportes e modos de leitura, meios, gêneros textuais e suas possibilidades de usos nas práticas sociais, colocando-nos diante de desafios frente a ausência de fronteiras entre o escrito e o eletrônico (agora digital). 
No bojo dessas transformações, as práticas atuais com o digital em rede convergem com os sistemas de mídias anteriores nos diversos eventos ou esferas da atividade humana (Backthin, 2011), seja individual ou seja coletiva, em domínios ou agências doméstica, pública, trabalho, escola, universidade, artes etc. Estas agências são condicionadas pela cultura, tecnologia, política e ideologia, e contribuem para a apropriação de uma multiplicidade de linguagens usadas pelos sujeitos em práticas sociais de comunicação e interação em diferentes espaços e tempos. Nestas práticas sociais, como aponta Buzato (2007) os sujeitos acionam modelos correspondentes a situações e fins específicos, relacionados aos usos do digital, por meio de competências para interatuar com estes conjuntos entrelaçados e mutuamente apropriáveis de códigos e tecnologias.

Para Buckinghan (2010) tais competências estão situadas nas suas dimensões subjetivas, intersubjetivas e objetivas, geralmente apreendidas social e culturalmente, com instituições formais e informais, consideradas agências de formação, e os seus sujeitos são os agenciadores dos processos que os levam a construção de conhecimentos que podemos conceber como letramentos digitais (LD). Tais conhecimentos contribuem para a formação letrada dos sujeitos em sintonia com as suas práticas cotidianas e podem ser potencializadas em processos de formação online na universidade.

Nas práticas formativas, segundo Santos (2006), tem sido cada vez mais crescente a busca de outros modos de fazer educação, se comunicar e promover aprendizagens, tanto na educação presencial, quanto na educação a distância, potencializando encontros a distância, face a face, ou em situações híbridas mediadas pelas tecnologias digitais. Como um evento da cibercultura, segundo a autora, a educação online se dá pela mediação das interfaces digitais que se configuram como espaços formativos "compartilhando informações, conhecimentos (...) com as interfaces e dispositivos de comunicação síncronas e assíncronas e de conteúdos hipertextuais disponíveis no ciberespaço a partir do AVA" "(Santos, 2006, p. 126).

2 Ambientes Virtuais de Aprendizagem (AVA) Virtual Learning Environment - softwares que auxiliam na montagem de cursos acessíveis pela Internet, com integração de interfaces textuais, gráficas e visuais, desenvolvidos para a gestão de artefatos digitais e organização do espaço, do tempo e dos meios digitais de comunicação. 
Em um processo de formação concebido como prática social que promove a comunicação com o uso das linguagens do meio digital há diversas implicações a serem levadas em conta. Para Freire (2011), deve se dar ênfase ao projeto de formação à "leitura do mundo" para a compreensão crítica da realidade. Nesse sentido, para o autor, são necessidades: aprender uma nova linguagem; levar em conta o tempo histórico e social em que os sujeitos se encontram; e instrumentar-se para a análise da realidade aberta às possibilidades que se pretende conhecer. Em uma perspectiva social dos LD, é fundamental levar o estudante ao uso das linguagens do digital em rede tendo em vista uma abordagem crítica, ou seja, para que a sua atuação seja consciente e transformadora.

$\mathrm{Na}$ perspectiva social e abordagem crítica dos LD as práticas de comunicação e de uso das linguagens são contextualizadas social, cultural e historicamente, com abertura para a formação do pensamento, da crítica e da autonomia dos sujeitos, tendo como ponto de partida e de chegada as práticas sociais em sua transversalidade e em continuum no decorrer da formação universitária.

\section{Considerações finais}

A ênfase da discussão sobre os letramentos digitais (LD) neste texto foi dada à dimensão da comunicação online, tendo em vista a diversidade de linguagens presente na cibercultura, visando também evidenciar habilidades e competências de uso destas linguagens que mobilizam outros letramentos pelos estudantes em suas práticas de formação na universidade.

Com as discussões sobre os processos comunicacionais no contexto mais amplo da cibercultura, em que a educação online abarca uma convergência de mídias (hipermidíatica, hipertextual e multimodal), os sujeitos aprendem e criam seus produtos culturais nos usos sociais cotidianos, desenvolvem competências e habilidades dos LD e empoderam-se para atuar criticamente com o digital em rede.

São práticas sociais em que diversos tipos de LD são mobilizados, relacionados aos diferentes contextos socioculturais e condições de sua produ- 
ção. Para o desenvolvimento de LD implica-se a apropriação das linguagens do meio digital em práticas com o uso destas em diversos meios, artefatos, interfaces e gêneros digitais. Estas práticas de comunicação online se dão por processos dialógicos e de interação entre os sujeitos, como princípios fundamentais para que o sentido e a significação do discurso sejam efetivos e ininterruptos.

Para que tais processos ocorram no contexto da comunicação online na universidade, destaca-se que as propostas de formação contemplem o desenvolvimento dos LD em uma perspectiva social (idealização, princípios, abordagens e práticas); engendrem as dimensões socioculturais, políticas e ideológicas (práticas sociais); considerem o meio cultural dos sujeitos envolvidos (domínio); tenham clareza do objeto a ser conhecido (competências e habilidades); e promovam o uso efetivo das linguagens do meio digital em uma abordagem crítica.

Outras implicações e perspectivas para problematizar o tema estão relacionadas a necessidade de formação de professores para os LD; equipes multidisciplinares para atuação conjunta; currículos que contemplem os LD de forma transversal; metodologias consoantes as necessidades da educação online; acompanhamento, ensino e aprendizagem e avaliação voltados ao exercício da cidadania crítica dos estudantes. Tais aspectos, são desenhados a partir de princípios epistemológicos e dinâmicas da cibercultura para potencializar os LD que os estudantes trazem ao chegar na universidade e mobilizar outros para fazer sentido à vida cotidiana dos estudantes na cibercultura.

\section{Referências bibliográficas}

BAKTHIN, M. (2011). Estética da Criação Verbal. São Paulo: Editora WMF: Martins Fontes.

BARTHES, R. (2004). O Rumor da Língua. São Paulo: Martins Fontes.

BUCKINGHAM. (2010). Cultura Digital, Educação Midiática e o Lugar da Escolarização. Revista Educação Real. Porto Alegre, vol. 35, n 3, p. 37- 58, set/dez.

BUZATO, M. E. K. (2007). Entre a Fronteira e a Periferia: linguagem e letramento na inclusão digital/Marcelo El Khouri Buzato. - Campinas, SP: [s.n.]. 
CHARTIER, R. (1998). A Aventura do Livro: do leitor ao navegador. São Paulo: Imprensa Oficial do Estado de São Paulo: Editora UNESP.

DeleuZE, G. (2010). Proust e os Signos. Rio de Janeiro: Forense Universitária.

FreIRE, P. (2011). Extensão ou Comunicação? 15 ed. São Paulo: Paz e Terra.

JENKINS, H. (2009). Cultura da Convergência.2 ed. São Paulo: Aleph.

MARCusCHI, L. A. (2006). A Análise da Conversação. São Paulo: Ática.

LEVY, P. (1993). As Tecnologias da Inteligência. Rio de Janeiro: Editora 34.

LEVY, P. (1999). Cibercultura. São Paulo: Editora 34.

SANTAELLA, L. (2004). Navegar no Ciberespaço: o perfil cognitivo do leitor imersivo. SãoPaulo: Paulus.

SANTAELLA, L. (2005). Matrizes da Linguagem e Pensamento: sonora, visual e verbal: aplicações na hipermídia. 3. ${ }^{a}$ Ed. São Paulo: Iluminuras: FAPESP.

SANTOS, E. O. (2006). Educação Online como Campo de Pesquisa-formação: potencialidades das interfaces digitais. In SANTOS, Edméa; ALVES, Lynn. Práticas Pedagógicas e Tecnologias Digitais. Rio de Janeiro: E- Papers.

SOUZA, T. F. M. (2016). Ondas em Ressonância: Letramentos Digitais de Estudantes na Universidade Aberta de Portugal. Tese de Doutorado. Centro de Educação. Programa de Pós-graduação em Educação. Universidade Federal de Santa Catarina. SREET, Brian (2014). Letramentos sociais: abordagens críticas do letramento no desenvolvimento, na etnografia e na educação. São Paulo: Parábola Editorial.

VigOTSKY, L. (1987). Pensamento e Linguagem. São Paulo: Martins Fontes. 